\title{
A cross-sectional study on the quality of life of patients with peripheral diabetic neuropathy pain in Hospital Tegku Ampaun Afzan, Kuantan, Malaysia
}

\author{
Sinan Mohammed Abdullah AL-Mahmood ${ }^{1 *}$, Tariq Abdul Razak ${ }^{2}$, Nik Nur \\ Fatnoon Nik Ahmad", Abdul Hadi Bin Mohamed ${ }^{2}$, Shahrin Tarmizi Bin Che \\ Abdullah ${ }^{2}$ \\ ${ }^{1}$ Kulliyyah of Nursing, ${ }^{2}$ Kulliyyah of Medicine, International Islamic University Malaysia, Bandar Indera Mahkota Campus, Jalan \\ Sultan Ahmad Shah, 25200 Kuantan, Pahang Darul Makmur, Malaysia
}

*For correspondence: Email: Sinan.almawla@gmail.com; Tel: 06001111002473

\begin{abstract}
Purpose: To evaluate the quality of life of patients with peripheral diabetic neuropathy pain (PDNP) in Hospital Tegku Ampaun Afzan (HTAA), Kuantan, Malaysia.

Methods: Ninety (90) participants were selected from the Medical Outpatient Department (MOPD) clinic of HTAA. The study adopted a cross-sectional design, and the self-administered Douleur Neuropathy 4 (DN4) and Audit of Diabetes-Dependent Quality of Life (ADDQoL) questionnaires were used for data collection.

Results: The negative impact of diabetes on QoL was clearly reflected in the fact that every domain had a negative mean value. Overall, $27.8 \%$ of the participants reported that DM negatively affected their QoL and $37.8 \%$ expressed the opinion that their QoL would have been higher if they were not diabetic. QoL correlated with marital status and age, with married participants and participants in the age range 50 - 59 years old showing QoL negatively affected $(p<0.05)$ by DM with PDNP. Apart from diabetes type, all other characteristics significantly affected participants QoL as reflected by the various related domains $(p<0.05)$.

Conclusion: Based on the findings of this study, it seems that individuals with diabetes and PDNP have a low QoL, with regard to "freedom to eat", "freedom to drink", "physical health", "family life", and "living condition".
\end{abstract}

Keywords: Quality of life, Diabetes, Peripheral neuropathy pain

\begin{abstract}
This is an Open Access article that uses a funding model which does not charge readers or their institutions for access and distributed under the terms of the Creative Commons Attribution License (http://creativecommons.org/licenses/by/4.0) and the Budapest Open Access Initiative (http://www.budapestopenaccessinitiative.org/read), which permit unrestricted use, distribution, and reproduction in any medium, provided the original work is properly credited.

Tropical Journal of Pharmaceutical Research is indexed by Science Citation Index (SciSearch), Scopus, International Pharmaceutical Abstract, Chemical Abstracts, Embase, Index Copernicus, EBSCO, African Index Medicus, JournalSeek, Journal Citation Reports/Science Edition, Directory of Open Access Journals (DOAJ), African Journal Online, Bioline International, Open-J-Gate and Pharmacy Abstracts
\end{abstract}

\section{INTRODUCTION}

Diabetes mellitus (DM) is one of the diseases with greater impact on public health, not only because of its high prevalence, but, above all, by the consequences of the chronic complications arising from this disease [1]. In 2017, the number of adults diagnosed with DM at global level was 425 million, according to the International Diabetes Federation (IDF) [2]. If no measures are 
adopted to deal with this situation, this figure is expected to rise to 642 million by 2040 [2]. Around $30 \%$ of hospitalised DM patients and 25 $\%$ of DM outpatients develop this condition [3]. Clinically, diabetic neuropathy (DN) manifests differently at somatic, autonomic and central levels and has a massive impact on quality of life as well as life expectancy [4]. According to the World Health Organisation (WHO), the manner in which people perceive their life condition within the cultural and value systems that they are living in and in relation to their aims, expectations, standards and worries is referred to as quality of life (QoL) [5]. An essential outcome of diabetes care, QoL is measured via the Audit of DiabetesDependent Quality of Life (ADDQoL) tool, which aims to determine how patients perceive that their QoL has been affected by diabetes [6]. Besides being a key outcome on its own, QoL is also a key outcome due to its implications for patients' ability to take care of themselves, which in turns affects how their diabetes is controlled and managed [7]. Knowledge about the QoL of individuals suffering from peripheral diabetic neuropathy pain (PDNP) is lacking, even though this aspect is clearly highly important. The relevant practitioners may assess how severe the disease is and how far along it advanced, but an incompatibility may occur between their perspective on patients' QoL and patients' perception of their QoL [8]. This is why patients' psychological state must be considered when inspecting QoL self-assessments [9]. Therefore, the present study seeks to assess the QoL of PDNP patients.

\section{METHODS}

\section{Setting and participants}

To achieve the aim of quantifying the QoL of PDNP patients, the study adopted a crosssectional design, and the self-administered DN4 and ADDQoL questionnaires were used for data collection. The location from which Ninety (90) participants were selected was the Medical Outpatient Department (MOPD) clinic of Hospital Tegku Ampaun Afzan (HTAA), Kuantan, Pahang, Malaysia. To be included in the study, participants had to be 18 years of age or older, received a DM diagnosis for over a year, and could read and write in English or Malay. Participants were not included if they suffered from a mental condition, like mental disorder, dementia, and Alzheimer's disease, or neuropathic pain caused by other diseases. Furthermore, to confirm that the pain was due to $\mathrm{DN}$, the participants had to exhibit four symptoms from the DN4 questionnaire, namely, burning, painful coldness, electric shock-like pain and painless symptoms like numbness, tingling, itching, and pins-and-needles.

Alongside the questionnaires, an information sheet was provided to all participants to inform them about the research goals. The questionnaires were distributed both in English and Malay, and the participants were requested to fill them out by themselves. No deadline for questionnaire completion was set. Participants were asked to sign an informed consent form (ICF) to confirm their agreement to take part and they were also offered the chance to pose any questions that they might have had. Besides the information derived from the two questionnaires, additional information regarding sociodemographic details and disease characteristics (e.g. type, duration, prescribed drugs) was obtained during interviews with the participants conducted as they waited to be consulted by the specialist.

\section{Ethical consideration}

The study was approved by the IIUM Research Ethics Committee (IREC-234), Ministry of Health of Malaysia (NMRR-14-188-19549), and followed the International Compilation of Human Research Standards [10]. As previously mentioned, the researcher informed the participants about the study goals and a consent form was distributed with the questionnaires. The information the participants provided in the questionnaires was kept confidential and only the collected data were processed. The data were not used for any other purpose, academic or otherwise, apart from the stated research aims.

\section{Instrument}

The ten items in the Douleur Neuropathy 4 (DN4) questionnaire were addressed by four questions; more specifically, seven of the item pertained to pain characterisation (e.g. burning, painful cold, electric shocks) and related unusual sensations (e.g., tingling, pins and needles, numbness, itching), while the remaining three items pertained to a succinct bedside neurological examination of the zone where pain occurred, which involved touch hypoaesthesia using a soft brush, pinprick hypoesthesia using disposable examination pins, and tactile dynamic allodynia using a soft brush. Depending on whether they were positive or negative, items were scored 1 or 0 , with the overall possible score being in the range 0-10. An overall score of 4 was established as the cut-off value for PDNP [11].

There are two general items that make up the ADDQoL questionnaire, namely, one item measuring QoL on the whole and another item 
consisting of 19 subitems inteded to determine how particular facets of life are affected by diabetes. These facets of life include, work life, recreational activities, holidays, local or longdistance trips, physical health, family life, ambitions, friendships and social relationships, close personal relationships, sex life, physical appearance, self-confidence, living coniditions, others' reactions, outlook on the future, financial status, reliance on others, and freedom to eat and to drink. In essence, the purpose of these 19 domains is to help the patients provide an assessment of their life and what would it be like if they were free from diabetes.

The impact rating for these domains and importance rating for perceived importance are in the range of -3 to +1 and 0 to +3 , respectively. The two ratings are multiplied to obtain a weighted score for every domain, which could be in the range of -9 to +3 . The lower the score, the poorer the QoL is. This is followed by the calculation of a mean weighted impact score (ADDQoL score) for the whole scale across all the domains of pertinence [12]. An earlier study has evaluated how valid and reliable the ADDQoL was, producing values of Cronbach's alpha of 0.945 for the Malay version and 0.907 for the English version [13].

\section{Sample size}

The Sample size was calculated using Eq 1.

$n=\left(Z^{2} \times P(1-P)\right) / e^{2}$

where $Z=$ value from standard normal distribution corresponding to desired confidence level $(Z=1.96$ for $95 \% \mathrm{Cl}), \mathrm{P}$ is expected exact proportion, e is desired precision (half desired $\mathrm{Cl}$ width). An additional $10 \%$ was added to the total sample for the possibility of incomplete questionnaires. The total sample size for our study based on these criteria required 85 (77 plus 8) [14].

\section{Statistical analysis}

The results were expressed as percentages and frequencies for categorical variables or by mean values and standard deviation for continuous variables. Independent samples t-test and oneway ANOVA were used to examine the differences in overall QoL and its domains regarding demographic variables and diseaserelated data. SPSS software version 20.0 (SPSS Inc, Chicago, IL, USA) was used for all data analysis. $P<0.05$ was considered significant in all the tests.

\section{RESULTS}

\section{Demographic characteristics of study participants}

Table 1 shows the sociodemographic and clinical features of the diabetics with PDNP included in this study. According to the results of the sociodemographic data analysis, most participants were male $(60 \%)$ in the age range 60 - 69 years old (51.1\%), who were married $(92.2 \%)$, out of work $(4.4 \%)$ and with an average financial status (51.1\%). Regarding clinical characteristics, most participants had type 1 diabetes mellitus (T1DM) (64.4\%) and had received their diagnosis a decade or more ago (44.4\%). Furthermore, 41 of the 90 participants received solely insulin-based treatment (45.6\%), 32 were prescribed oral hypoglycemic agents (35.6\%), and 17 received a mixture of the other two treatment approaches (18.9\%).

Table 1: Socio-demographic and clinical characteristics of PDNP

\begin{tabular}{|c|c|c|}
\hline Variables & $\mathrm{N}=90$ & $\%$ \\
\hline Gender & 54 & 60 \\
\hline Male & 36 & 40 \\
\hline Female & & \\
\hline \multicolumn{3}{|l|}{ Age group (yr) } \\
\hline$<50$ & 13 & 14.4 \\
\hline $50-59$ & 23 & 25.6 \\
\hline $60-69$ & 46 & 51.1 \\
\hline$>69$ & 8 & 8.9 \\
\hline \multicolumn{3}{|l|}{ Occupation } \\
\hline Unemployed & 50 & 55.6 \\
\hline Employed & 40 & 44.4 \\
\hline \multicolumn{3}{|l|}{ Marital status } \\
\hline Married & 83 & 92.2 \\
\hline Single & 7 & 7.8 \\
\hline \multicolumn{3}{|l|}{ Economic status } \\
\hline Poor & 28 & 31.1 \\
\hline Moderate & 46 & 51.1 \\
\hline Good & 16 & 17.8 \\
\hline \multicolumn{3}{|l|}{ Type of diabetes } \\
\hline Type I & 58 & 64.4 \\
\hline Type II & 32 & 35.6 \\
\hline \multicolumn{3}{|l|}{ Duration of diabetes } \\
\hline 1-4 years & 19 & 21.1 \\
\hline $5-9$ years & 31 & 34.4 \\
\hline$\geq 10$ years & 40 & 44.4 \\
\hline \multicolumn{3}{|l|}{ Type of medication } \\
\hline OHA only & 32 & 35.6 \\
\hline Insulin only & 41 & 45.6 \\
\hline $\begin{array}{l}\text { Combination } \\
\text { (biguanide+insulin) }\end{array}$ & 17 & 18.9 \\
\hline
\end{tabular}

\section{Impact of diabetes on QoL domains}

The negative impact of diabetes on QoL was clearly reflected in the fact that every domain had a negative mean value. Overall, $27.8 \%$ of the 
participants reported that DM negatively affected their QoL and $37.8 \%$ expressed the opinion that their QoL would have been higher if they had not been diabetics. Table 2 indicates how the answers were distributed and the weights allocated to the impact ratings. The domains most affected by DM with PDNP were "freedom to eat" (mean impact rating: $-2.74 \pm 0.53$ ), " freedom to drink" (mean impact rating: $-2.70 \pm$ 0.46 ), "physical health" (mean impact rating: $2.49 \pm 0.92$ ), "family life" (mean impact rating: $2.24 \pm 1.17$ ) and "living condition" (mean impact rating: $-2.22 \pm 1.03)$. By contrast, the domains least affected by DM were "holidays" (mean impact rating: $-0.83 \pm 1.26)$, "physical appearance" (mean impact rating: $-0.96 \pm 1.23$ ), "working life" (mean impact rating: -1.12 \pm 1.135), "people's reaction" (mean impact rating: $-1.27 \pm 1.17$ ) and "sex life" (mean impact rating: $-1.32 \pm 1.18)$. Furthermore, the domains that the participants attributed the greatest and lowest importance were respectively "freedom to eat" (mean $2.87 \pm 0.34$ ) and "dependence on others" (mean $0.11 \pm 0.31$ ). These two domains were also found to be the QoL domains impacted to the greatest and least degree by DM, with mean $-7.95 \pm 1.94$ for "freedom to eat" and mean -0.27 \pm 0.84 for "dependence on others".

\section{Impact of sociodemographic and clinical features on overall QoL score}

Table 3 presents the results obtained regarding discrepancies in the overall QoL and its domains associated with demographic and clinical variables. According to the results of the independent t-test and one-way ANOVA, QoL was found to be correlated with marital status and age; thus, married participants and participants in the age range 50 - 59 years old had their QoL significantly $(p<0.05)$ negatively affected by DM with PDNP. By contrast, QoL was not observed to be statistically significantly correlated with gender, occupation, economic status, diabetes type or duration, and medication type $(p>0.05)$.

Table 2: Distribution of responses $(\mathrm{N}=90)$ by impact and importance rating together with weighted impact score

\begin{tabular}{|c|c|c|c|c|c|c|c|}
\hline \multirow[b]{2}{*}{$\mathbf{Q}$} & \multirow[b]{2}{*}{ Domain } & \multirow{2}{*}{$\begin{array}{c}\text { Impact rating } \\
\text { mean } \pm \text { SD }\end{array}$} & \multirow[b]{2}{*}{ (range) } & \multirow{2}{*}{$\begin{array}{l}\text { Importance } \\
\text { rating } \\
\text { mean士 SD }\end{array}$} & \multirow[b]{2}{*}{ (range) } & \multirow{2}{*}{$\begin{array}{c}\text { Weighted impact } \\
\text { score } \\
\text { mean } \pm \text { SD }\end{array}$} & \multirow[b]{2}{*}{ (range) } \\
\hline & & & & & & & \\
\hline 1 & Leisure activities & $-1.94 \pm 1.14$ & $\left(-3 \_0\right)$ & $1.91 \pm 1.21$ & $\left(-3 \_3\right)$ & $-4.73 \pm 3.71$ & $\left(-9 \_3\right)$ \\
\hline 2 & Working life & $-1.12 \pm 1.35$ & $\left(-3 \_0\right)$ & $1.22 \pm 1.40$ & $\left(0 \_3\right)$ & $-3.12 \pm 4.02$ & $(-9-0)$ \\
\hline 3 & Journeys & $-1.99 \pm 1.40$ & $\left(-3 \_3\right)$ & $2.51 \pm 0.76$ & $\left(0 \_3\right)$ & $-5.51 \pm 4.03$ & $\left(-9 \_6\right)$ \\
\hline 4 & Holidays & $-0.83 \pm 1.26$ & $\left(-3 \_0\right)$ & $0.89 \pm 1.29$ & $\left(0 \_3\right)$ & $-2.14 \pm 3.71$ & $\left(-9 \_0\right)$ \\
\hline 5 & Physical health & $-2.49 \pm 0.92$ & $\left(-3 \_0\right)$ & $2.63 \pm 0.77$ & $\left(0 \_3\right)$ & $-7.03 \pm 2.90$ & $\left(-9 \_0\right)$ \\
\hline 6 & Family life & $-2.24 \pm 1.17$ & $\left(-3 \_3\right)$ & $2.54 \pm 0.85$ & $\left(0 \_3\right)$ & $-6.17 \pm 3.43$ & $\left(-9 \_0\right)$ \\
\hline 7 & $\begin{array}{l}\text { Friendship and } \\
\text { social life }\end{array}$ & $-1.76 \pm 1.11$ & $\left(-3 \_0\right)$ & $1.64 \pm 1.06$ & $\left(0 \_3\right)$ & $-3.73 \pm 3.37$ & $\left(-9 \_0\right)$ \\
\hline 8 & $\begin{array}{l}\text { Personal } \\
\text { relationship }\end{array}$ & $-1.48 \pm 1.14$ & $\left(-3 \_0\right)$ & $1.67 \pm 1.02$ & (0_3) & $-3.45 \pm 3.47$ & $\left(-9 \_0\right)$ \\
\hline 9 & Sex life & $-1.32 \pm 1.18$ & $\left(-3 \_3\right)$ & $1.44 \pm 0.86$ & (0_3) & $-2.47 \pm 2.99$ & $\left(-9 \_6\right)$ \\
\hline 10 & $\begin{array}{l}\text { Physical } \\
\text { appearance }\end{array}$ & $-0.96 \pm 1.23$ & $\left(-3 \_0\right)$ & $1.36 \pm 1.23$ & (0_3) & $-2.21 \pm 3.35$ & $\left(-9 \_0\right)$ \\
\hline 11 & Self-confidence & $-1.49 \pm 1.15$ & $\left(-3 \_0\right)$ & $1.61 \pm 1.12$ & (0_3) & $-3.22 \pm 3.50$ & $\left(-9 \_0\right)$ \\
\hline 12 & Motivation & $-1.38 \pm 1.23$ & $\left(-3 \_3\right)$ & $1.54 \pm 1.12$ & (0_3) & $-2.98 \pm 3.33$ & $\left(-9 \_0\right)$ \\
\hline 13 & People's reaction & $-1.27 \pm 1.17$ & $\left(-3 \_0\right)$ & $1.37 \pm 1.08$ & (0_3) & $-2.63 \pm 3.39$ & $\left(-9 \_0\right)$ \\
\hline 14 & $\begin{array}{l}\text { Feeling about } \\
\text { future }\end{array}$ & $-1.79 \pm 1.17$ & $\left(-3 \_0\right)$ & $1.62 \pm 1.16$ & (0_3) & $-3.85 \pm 3.54$ & $\left(-9 \_0\right)$ \\
\hline 15 & $\begin{array}{l}\text { Financial } \\
\text { situation }\end{array}$ & $-1.83 \pm 1.16$ & $\left(-3 \_0\right)$ & $2.04 \pm 1.14$ & (0_3) & $-4.31 \pm 3.80$ & $\left(-9 \_0\right)$ \\
\hline 16 & Living condition & $-2.22 \pm 1.03$ & $\left(-3 \_0\right)$ & $2.51 \pm 0.83$ & (0_3) & $-6.05 \pm 3.40$ & $\left(-9 \_0\right)$ \\
\hline 17 & $\begin{array}{l}\text { Dependence on } \\
\text { others }\end{array}$ & $-1.88 \pm 1.21$ & $\left(-3 \_0\right)$ & $0.11 \pm 0.31$ & (0_3) & $-0.27 \pm 0.84$ & $\left(-3 \_0\right)$ \\
\hline 18 & Freedom to eat & $-2.74 \pm 0.53$ & $\left(-3 \_0\right)$ & $2.87 \pm 0.34$ & (2_3) & $-7.95 \pm 1.94$ & $\left(-9 \_0\right)$ \\
\hline 19 & $\begin{array}{l}\text { Freedom to } \\
\text { drink }\end{array}$ & $-2.70 \pm 0.46$ & $(-3--2)$ & $2.73 \pm 0.46$ & (1_3) & $-7.47 \pm 2.04$ & $(-9-2)$ \\
\hline
\end{tabular}


Table 3: Average weighted impact scores by sociodemographic and clinical characteristics of diabetic patients with PDNP

\begin{tabular}{|c|c|c|}
\hline \multirow[b]{2}{*}{ Variable } & \multicolumn{2}{|c|}{$\begin{array}{l}\text { Average weighted impact } \\
\text { score }\end{array}$} \\
\hline & Mean \pm SD & $P$-value \\
\hline Gender & & 0.814 \\
\hline Male & $-4.13 \pm 1.77$ & \\
\hline Female & $-4.24 \pm 2.25$ & \\
\hline Age group (yr) & & 0.017 \\
\hline$<50$ & $-4.15 \pm 1.28$ & \\
\hline $50-59$ & $-4.94 \pm 2.22^{x}$ & \\
\hline $60-69$ & $-4.10 \pm 1.97$ & \\
\hline$>69$ & $-2.43 \pm 0.73$ & \\
\hline Occupation & & 0.903 \\
\hline Unemployed & $-4.20 \pm 2.16$ & \\
\hline Employed & $-4.15 \pm 1.72$ & \\
\hline Marital status & & 0.000 \\
\hline Married & $-4.28 \pm 2.00^{\star}$ & \\
\hline Single & $-2.89 \pm 0.62$ & \\
\hline Economic status & & 0.122 \\
\hline Poor & $-3.95 \pm 1.52$ & \\
\hline Moderate & $-3.99 \pm 2.00$ & \\
\hline Good & $-5.09 \pm 2.37$ & \\
\hline Type of diabetes & & 0.171 \\
\hline Type I & $-4.39 \pm 1.95$ & \\
\hline Type II & $-3.79 \pm 1.96$ & \\
\hline Duration of diabetes & & 0.157 \\
\hline $1-4$ years & $-4.04 \pm 1.61$ & \\
\hline $5-9$ years & $-4.71 \pm 2.15$ & \\
\hline$\geq 10$ years & $-3.82 \pm 1.92$ & \\
\hline Type of medication & & 0.067 \\
\hline OHA only & $-3.79 \pm 1.96$ & \\
\hline Insulin only & $-4.69 \pm 2.04$ & \\
\hline $\begin{array}{l}\text { Combination } \\
\text { (biguanide+insulin) }\end{array}$ & $-3.64 \pm 1.54$ & \\
\hline
\end{tabular}

Impact of sociodemographic and clinical features on QoL domains

Table 4 lists the average weighted impact scores associated with participants' sociodemographic and clinical characteristics (i.e., gender, age group, occupation, marital status, economic status, diabetes type and duration, and type of medication). Apart from diabetes type, all other characteristics significantly affected participants QoL as reflected by the various related domains $(p<0.05)$.

\section{DISCUSSION}

Overall, the results of the ADDQoL questionnaire revealed that every domain related to participants' QoL was adversely affected by diabetes. As far as the researcher is aware, no other study has addressed the QoL of individuals with diabetes and PDNP in Malaysia. To determine the QoL of these individuals, the study investigated their sociodemographic and clinical features, and found that the participants' QoL was low-to-moderate, according to the mean score of the overall QoL and related domains. The study employed the popular tool of ADDQoL questionnaire to gain a comprehensive understanding of QoL among individuals with diabetes $[12,13,15]$.

The findings revealed that the QoL domain of "freedom to eat" was adversely affected by diabetes to the highest degree, reflecting the major impact of diet limitations on QoL. This corroborated the results of previous studies $[16,17]$. Furthermore, diabetes with PDNP also had a significant negative effect on the QoL domain "freedom to drink". By contrast, the lowest impact of diabetes was recorded in the case of the "holiday" domain. This was inconsistent with the findings of earlier studies $[13,15]$, which reported that the domains least impacted were "people's reaction" and "working life".

Solely age and marital status out of participants' sociodemographic and clinical features were found to significantly impact QoL, as indicated by the average weighted impact scores. Individuals with ages between 50 and 59 years old were more likely to experience a lower QoL. This was consistent with the findings of two other studies $[18,19]$, which reported a direct correlation between younger age and lower ADDQoL scores as well as a more extensive adverse effect on QoL among individuals with diabetes. This paradox may be due to the fact that, unlike older diabetics, younger diabetics are more anxious about their future and the implications of their disease for their life [12]. In addition, a close correlation between marital status and poorer QoL was also observed in the present study. This was inconsistent with the result of a previous study [18], which did not find a significant correlation between marital status and lower ADDQoL scores. The reason for this might be due to the fact that diabetics' sexual activity might be diminished by PDN.

Many of the 19 domains in the ADDQoL questionnaire were significantly affected by the participants' sociodemographic and disease features. However, among the two genders, a higher QoL was registered in the case of male participants. Indeed, the "living condition" domain was significantly impacted by the variable of male gender, while the "motivation", "people's reaction" and "feeling about future" domains were significantly impacted by the variable of female gender. Other studies also reported that male diabetics enjoyed a better QoL compared to female diabetics [20]. 
Table 4: Impact of socio-demographic and clinical characteristics on individual life domains

\begin{tabular}{|c|c|c|c|c|c|}
\hline \multirow[t]{3}{*}{ Item of significance } & \multicolumn{4}{|c|}{ Variable (mean \pm SD) } & $P$-value \\
\hline & \multicolumn{4}{|c|}{ Gender } & \\
\hline & \multicolumn{2}{|c|}{ Male } & \multicolumn{2}{|c|}{ Female } & \\
\hline Motivation & \multicolumn{2}{|c|}{$-2.35 \pm 3.06$} & \multicolumn{2}{|c|}{$-3.94 \pm 3.53^{*}$} & 0.031 \\
\hline People's reaction & \multicolumn{2}{|c|}{$-1.94 \pm 3.04$} & \multicolumn{2}{|c|}{$-3.66 \pm 3.66^{\star}$} & 0.023 \\
\hline Feeling about future & \multicolumn{2}{|c|}{$-3.25 \pm 3.65$} & \multicolumn{2}{|c|}{$-4.75 \pm 3.22^{*}$} & 0.045 \\
\hline \multirow[t]{3}{*}{ Living condition } & -6.7 & $3.10^{*}$ & -5.0 & 3.61 & 0.023 \\
\hline & \multicolumn{4}{|c|}{ Age group (yr) } & \\
\hline & $<50$ & $50-59$ & $60-69$ & $>69$ & \\
\hline Holidays & $-0.07 \pm 0.277$ & $-3.26 \pm 4.23^{*}$ & $-2.54 \pm 3.94$ & - & 0.023 \\
\hline Friendship and social life & $-3.92 \pm 3.49$ & $-5.69 \pm 3.67^{*}$ & $-3.17 \pm 2.92$ & $-1.00 \pm 1.85$ & 0.002 \\
\hline Personal relationship & $-2.00 \pm 3.16$ & $-5.78 \pm 3.55^{*}$ & $-3.13 \pm 3.14$ & $-1.00 \pm 1.85$ & 0.000 \\
\hline Sex life & $-1.76 \pm 3.32$ & $-3.86 \pm 2.75^{\star}$ & $-2.39 \pm 2.99$ & $-0.12 \pm 0.35$ & 0.012 \\
\hline Physical appearance & $-2.53 \pm 3.23$ & $-3.86 \pm 3.59^{\star}$ & $-1.65 \pm 3.24$ & $-0.12 \pm 0.35$ & 0.015 \\
\hline Self-confidence & $-4.30 \pm 3.63$ & $-5.30 \pm 3.87^{*}$ & $-2.34 \pm 2.93$ & $-0.50 \pm 0.75$ & 0.000 \\
\hline Motivation & $-4.15 \pm 3.78$ & $-4.52 \pm 3.57^{*}$ & $-2.39 \pm 2.91$ & $-0.12 \pm 0.35$ & 0.002 \\
\hline Feeling about future & $-5.38 \pm 3.37$ & $-6.00 \pm 2.71^{*}$ & $-2.97 \pm 3.48$ & $-0.25 \pm 0.46$ & 0.000 \\
\hline \multirow[t]{3}{*}{ Financial situation } & $-5.23 \pm 3.13^{*}$ & $-4.65 \pm 4.16$ & $-4.58 \pm 3.75$ & $-0.25 \pm 0.70$ & 0.014 \\
\hline & \multicolumn{4}{|c|}{ Occupation } & \\
\hline & \multicolumn{2}{|c|}{ Unemployed } & \multicolumn{2}{|c|}{ Employed } & \\
\hline Working life & \multicolumn{2}{|c|}{$-1.40 \pm 3.21$} & \multicolumn{2}{|c|}{$-5.27 \pm 3.92^{*}$} & 0.000 \\
\hline Physical appearance & \multicolumn{2}{|c|}{$-2.88 \pm 3.67^{*}$} & \multicolumn{2}{|c|}{$-1.37 \pm 2.71^{*}$} & 0.028 \\
\hline Self-confidence & -3.88 & $3.69^{*}$ & -2.4 & 3.10 & 0.042 \\
\hline & & Marita & tatus & & \\
\hline & & ied & & & \\
\hline Friendship and social life & -3.92 & $3.41^{*}$ & -1.4 & 1.90 & 0.012 \\
\hline Personal relationship & -3.62 & $3.52^{*}$ & -1.4 & 1.90 & 0.023 \\
\hline Sex life & -2.63 & $3.06^{*}$ & -0.5 & 0.78 & 0.000 \\
\hline Physical appearance & -2.37 & $3.43^{*}$ & -0.2 & 0.48 & 0.000 \\
\hline Self-confidence & -3.46 & $3.53^{\star}$ & -0.2 & 0.48 & 0.000 \\
\hline Motivation & -3.21 & $3.37^{*}$ & -0.2 & 0.48 & 0.000 \\
\hline People's reaction & -2.83 & $3.45^{\star}$ & -0.2 & 0.48 & 0.000 \\
\hline Feeling about future & -4.16 & $3.51^{*}$ & -0.1 & 0.37 & 0.000 \\
\hline Financial situation & -4.56 & $3.80^{*}$ & -1.2 & 2.21 & 0.006 \\
\hline Living condition & & $90 \pm 3.45$ & -7.8 & $2.03^{*}$ & 0.048 \\
\hline & & Econon & status & & \\
\hline & Poor & Moderate & & & \\
\hline Working life & $-2.92 \pm 3.72$ & $-2.47 \pm 3.88$ & -5.3 & $4.42^{*}$ & 0.049 \\
\hline Living condition & $-6.80 \pm 3.22$ & $-5.08 \pm 3.40$ & -7.3 & $2.80^{*}$ & 0.018 \\
\hline Freedom to eat & $-7.53 \pm 1.95$ & $-8.56 \pm 1.32^{*}$ & -6.9 & 2.76 & 0.005 \\
\hline & & Duration of & betes (yr) & & \\
\hline & $1-4$ & $5-9$ & & & \\
\hline Leisure activities & $-2.78 \pm 2.37$ & $-5.12 \pm 3.81$ & -5.3 & $3.91^{*}$ & 0.034 \\
\hline People's reaction & $-2.10 \pm 3.03$ & $-4.16 \pm 3.88^{*}$ & -1.7 & 2.74 & 0.006 \\
\hline Financial situation & $-5.36 \pm 3.98^{*}$ & $-5.22 \pm 3.59$ & -3.1 & 3.60 & 0.024 \\
\hline & & Type of $r$ & dication & & \\
\hline & OHA only & Insulin only & Com & lation & \\
\hline Leisure activities & $-3.81 \pm 3.47$ & $-5.92 \pm 3.43^{\star}$ & -3.5 & 4.13 & 0.018 \\
\hline Physical appearance & $-1.81 \pm 3.12$ & $\begin{array}{c}-3.09 \pm 3.67^{*} \\
\text { Type of }\end{array}$ & betes & 2.32 & 0.042 \\
\hline & & & & & \\
\hline All items & & & & & $>0.05$ \\
\hline
\end{tabular}

Furthermore, by contrast to participants younger than 60 years of age, those older than 60 years of age had a better social life. Meanwhile, an earlier study revealed that a higher QoL was enjoyed by diabetics younger than 50 years of age [17].

Four of the 19 domains were significantly affect- ed by the clinical characteristics of diabetes duration and types of medication. More specifically, the domains of "financial situation", "people's reaction", and "leisure activities" were affected by diabetes duration. Conversely, an earlier study [17] reported that it was the "selfconfidence", "sexual life" and "holidays" domains that were significantly affected by diabetes 
duration. Meanwhile, in the present study, "leisure activities" and "physical appearance" were adversely impacted by insulin treatment.

Again, this result differed from that of earlier studies [21,22], which found that the QoL domains affected by insulin treatment were "family relationships", "sex life", "travel", and "family future". These inconsistencies between the present study and earlier ones might be due to cultural and context-related aspects, discrepancies in participants' sociodemographic characteristics, and differences in the assessment tools employed [23].

\section{Limitations of the study}

Generalisation of the study results to the wider population of Kuantan was not possible because data were collected from just one, albeit major, hospital in the city. The study results might also be somewhat distorted by the fact that data were derived from self-reported questionnaires, which present the risk of participants underestimating or exaggerating their health-related QoL.

\section{CONCLUSION}

The findings of this study indicate that individuals with diabetes and PDNP have a low QoL, particularly, with regard to "freedom to eat", "freedom to drink", "physical health", "family life", and "living condition". Certain ADDQoL domain scores are adversely impacted by factors such as female sex, younger age, lack of employment, marriage, good financial position, diabetes duration, and insulin-based treatment.

Therefore, not all domains are equally affected by the same sociodemographic and clinical features. This fact must be taken into account to effectively address each patient's needs. Doctors and healthcare practitioners may find these results useful in formulating effective approaches and strategies for enhancing patients' QoL. To further reinforce the results, the study should be repeated on a larger scale with a longer follow-up interval. Future studies should also address the management of individuals suffering from PDNP as well as assess the outcomes of different medical interventions.

\section{DECLARATIONS}

\section{Acknowledgement}

This work was sponsored by International Islamic University Malaysia (no. RIGS 16-286-0450).

\section{Conflict of interest}

The authors have no conflict of interest to declare with regard to this work.

\section{Contribution of authors}

The authors declare that this work was done by the authors named in this article and all liabilities pertaining to claims relating to the content of this article will be borne by them. All authors participated in the designing, collecting of data, analysis and writing of this article.

\section{REFERENCES}

1. Isla PP. Chronic complications of diabetes mellitus: Prevention and management. Rev Enferm 2012; 35(9): 46-52.

2. Atlas TID. IDF Diabetes Atlas Eighth Edition. http://wwwidforg/idf-diabetes-atlas-seventh-edition 2015; 43-44.

3. Pippitt K, Li M, Gurgle HE. Diabetes Mellitus: Screening and Diagnosis. Am Fam Physician 2016; 93(2): 103109.

4. Squadrito G, Cucinotta $D$. The late complications of diabetes mellitus. Annali italiani di medicina interna: organo ufficiale della Societa italiana di medicina interna 1990; 6(1 Pt 2): 126-136.

5. Group TW. The World Health Organization quality of life assessment (WHOQOL): development and general psychometric properties. Soc Sci Med 1998; 46(12): 1569-1585.

6. Bradley C, Todd C, Gorton T, Symonds E, Martin A, Plowright $R$. The development of an individualized questionnaire measure of perceived impact of diabetes on quality of life: the ADDQoL. Qual Life Res 1999; 8(12): 79-91.

7. Singh $H$, Bradley $C$. Quality of life in diabetes. Int $J$ Diabetes Dev Countries 2006; 26(1): 7-10.

8. Peyrot M, Rubin RR, Lauritzen T, Snoek FJ, Matthews DR, Skovlund SE. Psychosocial problems and barriers to improved diabetes management: results of the Cross-National Diabetes Attitudes, Wishes and Needs (DAWN) Study. Diabet Med 2005; 22(10): 1379-1385.

9. Spasić A, Radovanović RV, Đorđević AC, Stefanović N, Cvetković T. Quality of Life in Type 2 Diabetic Patients. Acta Facultatis Medicae Naissensis 2014; 31(3): 193200.

10. Health UDo, Services H. International compilation of human research standards. DHHS Washington; 2014; P140

11. Spallone V, Morganti R, D'amato C, Greco C, Cacciotti L, Marfia G. Validation of DN4 as a screening tool for neuropathic pain in painful diabetic polyneuropathy. Diabet Med 2012; 29(5): 578-585.

12. Papazafiropoulou AK, Bakomitrou F, Trikallinou A, Ganotopoulou A, Verras C, Christofilidis G, Bousboulas 
S, Melidonis A. Diabetes-dependent quality of life (ADDQOL) and affecting factors in patients with diabetes mellitus type 2 in Greece. BMC Res Notes 2015; 8(1): 1-6.

13. Jannoo Z, Yap BW, Musa KI, Lazim MA, Hassali MA. An audit of diabetes-dependent quality of life in patients with type 2 diabetes mellitus in Malaysia. Qual Life Res 2015; 24(9): 2297-2302.

14. Suresh K, Chandrashekara S. Sample size estimation and power analysis for clinical research studies. J Hum Reprod Sci 2012; 5(1): 7-13.

15. Turk E, Rupel VP, Tapajner A, Leyshon S, Isola A. An audit of diabetes-dependent quality of life (ADDQOL) in older patients with diabetes mellitus type 2 in Slovenia. Value in Health Regional Issues 2013; 2(2): 248-253.

16. Bradley C, Speight J. Patient perceptions of diabetes and diabetes therapy: assessing quality of life. Diabetes Metab Res Rev 2002; 18(S3): 64-69.

17. Holmanová E, Žiaková K. Audit Diabetes-Dependent Quality of Life questionnaire: usefulness in diabetes self-management education in the Slovak population. $J$ Clin Nursing 2009; 18(9): 1276-1286.
18. Chung JO, Cho DH, Chung DJ, Chung MY. Assessment of factors associated with the quality of life in Korean type 2 diabetic patients. Intern Med 2013; 52(2): 179185.

19. Wang H-F, Yeh MC. The quality of life of adults with type 2 diabetes in a hospital care clinic in Taiwan. Qual Life Res 2013; 22(3): 577-584.

20. Rubin RR, Peyrot M. Quality of life and diabetes. Diabetes Metab Res Rev 1999; 15(3): 205-218.

21. Demirci H, Cinar Y, Bayram N, Bilgel N. Quality of life in type II diabetic patients in primary health care. Dan Med J 2012; 59(10): 1-5.

22. Kong D, Ding Y, Zuo X, Su W, Xiu L, Lin M, Rao S, Yu S. Adaptation of the Audit of Diabetes-Dependent Quality of Life questionnaire to people with diabetes in China. Diabetes Res Clin Pract 2011; 94(1): 45-52.

23. Didarloo A, Alizadeh M. Health-Related Quality of Life and its Determinants Among Women With Diabetes Mellitus: A Cross-Sectional Analysis. Nursing midwifery studies 2016; 5(1): 1-7. 